\title{
O grupo psicoterapêutico no Caps
}

\author{
The psychotherapeutic group in the CAPS
}

Cassandra Cardoso 1

Nedio Seminotti 1

\footnotetext{
1 Programa de

Pós-Graduação em

Psicologia da PUCRS.

Av. Ipiranga 6681, prédio

11,9 o andar, sala 939 ,

Partenon, 90619-900,

Porto Alegre RS.

cassandcardoso@yahoo.com
}

Abstract This article presents the results of a research which aimed at investigating the belongings to bonds of users of a psychotherapeutic group in a Psychosocial Aid Center (Caps). The methodology was qualitative. The qualitative textual analysis was applied to the corpus, which was built with the use of the participant observation technique, consisted of reports of eight psychotherapeutic group sessions, which were recorded and transcribed. The characterization of both the group and the research participants was based on the observer's records. The research was carried out from a bonding viewpoint, considering the complexity of the empiric universe. The central argument of this analysis has emerged from the discussion of the results, indicating that multiple belongings of the group users were related to bonds in their psychotherapeutic group as well as the ones they had in Caps, in the psychiatric hospital, in their families and in society.

Key words Caps, Psychotherapeutic group, Bonds, Belongings
Resumo Neste artigo, são apresentados os resultados de uma pesquisa que investigou as pertenças aos vínculos em usuários de um grupo psicoterapêutico em um Centro de Atenção Psicossocial (Caps). É utilizada a metodologia qualitativa. O corpus, construído a partir da técnica de observação participante, consistiu em relatos provenientes da transcrição de gravações em áudio de oito sessões do grupo psicoterapêutico. Sua análise foi realizada através da análise textual qualitativa. O diário de campo da observadora baseou a caracterização do grupo e dos participantes da pesquisa, realizada a partir de uma perspectiva vincular, contemplando a complexidade do universo empírico. Da discussão dos resultados emergiu o argumento central da análise, indicando que as múltiplas pertenças dos usuários do grupo investigado referem-se a vínculos em seu grupo terapêutico e, também, a vínculos no Caps, no hospital psiquiátrico, na família e na sociedade.

Palavras-chave Caps, Grupo psicoterapêutico, Vínculos, Pertenças. 


\section{Introdução}

Na pesquisa apresentada neste artigo, buscamos conhecer e identificar as pertenças aos vínculos em usuários de um dos grupos psicoterapêuticos de um Centro de Atenção Psicossocial (Caps), apreender como se constitui o sentimento de pertença dos usuários ao grupo e verificar se há construção de novos vínculos e pertenças no grupo.

Os Caps são unidades de atendimento em saúde mental que oferecem a seus usuários um programa de cuidados intensivos, elaborado por uma equipe multidisciplinar. Inicialmente concebidos como alternativas terapêuticas ao modelo de atendimento centrado no hospital psiquiátrico, os Caps passaram a ter, desde 2002, a função estratégica de articular as forças de atenção em saúde e as da comunidade, visando à promoção da vida comunitária e da autonomia de seus usuários ${ }^{1}$ (de acordo com a Portaria 336/GM, de 20042). Daí a importância de problematizar e incentivar a discussão dessas práticas pela sociedade, visando a otimização dos recursos financeiros investidos pelo Esta$\mathrm{do}^{3} \mathrm{e}$ a formação de um sistema complexo para que se evite a mera substituição de um modelo centralizador por outro.

O Caps no qual esta pesquisa foi realizada está classificado como Caps II, segundo a Portaria 336/GM do Ministério da Saúde2, e presta atendimento a adultos com transtornos mentais severos e persistentes, egressos ou não de internações psiquiátricas ou de outros serviços de saúde. Localiza-se em Passo Fundo, no Rio Grande do Sul, um município de aproximadamente 170 mil habitantes, e também atende a municípios vizinhos com menos de 20 mil habitantes.

De acordo com a orientação do Ministério da Saúde (Portaria 224/92, de 20014; e Portaria no 336/GM, de 20042) e com a tendência mundial das reformas psiquiátricas, os atendimentos são realizados predominantemente em grupos 5 nos Caps pelo intercâmbio inédito que o grupo proporciona a seus integrantes, possibilitando a improvisação de novos modos de relação6, 7. Por sua vez, o suporte oferecido aos usuários com transtornos mentais graves, por centros de atendimento diurno, configura o Caps como um local propício para a realização de psicoterapias orientadas para o insight $5,8,9$.

Entre os resultados de uma pesquisa longitudinal que investigou a mudança psíquica em esquizofrênicos, efetuada através do atendimento psicoterapêutico de grupo, está a facili- tação de vínculos interpessoais 10 . Nesta pesquisa, problematizamos a questão da vincularidade, aqui entendida como produção de relações entre sujeitos ${ }^{11}$, em um grupo de um Caps.

O tema foi abordado a partir de uma perspectiva vincular, proposta pela psicanálise das configurações vinculares, uma teorização sulamericana em psicanálise, que amplia o seu campo de atuação ao considerar as relações entre os sujeitos 11,12,13. O vínculo é uma estrutura inconsciente que liga dois ou mais sujeitos em uma relação de presença, constituindo-os como sujeitos do vínculo ${ }^{14}$. Como a estrutura vincular é inconsciente, seu registro pelo sujeito se dá pelo sentimento de pertença, que designa a ocupação de um lugar pelo sujeito na estrutura vincular. A pertença não é definitiva, deve ser constantemente renovada pelo próprio sujeito e reconhecida pelos outros sujeitos vinculados. E o sujeito precisa justificar sua ocupação de um lugar na estrutura vincular, mantendo seu status de presença e acreditando compartilhar objetivos e idéias com os outros sujeitos vinculados ${ }^{15}$.

Por se constituir nos múltiplos vínculos a que pertence, o sujeito é considerado múltiplo, tendo múltiplas origens ao longo de sua vida, além das primeiras relações. Alguns vínculos são considerados como origens, por inscrever no sujeito algo que não existia anteriormente, modificando-o, suplementando-o, tornando-o um outro sujeito, que não estava previsto na infância. Nesse contexto, o enquadre grupal é considerado como próprio da vincularidade, sendo potencialmente terapêutico ${ }^{16}$. A realização de seu potencial constitui-se na medida em que as relações em seu interior estimulam em seus participantes a constante produção de novos vínculos e pertenças e, dessa forma, de sujeitos.

\section{Método}

\section{$O$ contexto dos participantes}

Desde o início do funcionamento desse Caps, as atividades em grupo são intensas e diversificadas. O grupo investigado é definido como psicoterapêutico pela equipe técnica da instituição. Alguns usuários estão em tratamento há mais de 10 anos no Caps, uns ininterruptamente, e outros tendo interrompido e retomado sua participação, o que permite que a maioria deles se conheça. Sua freqüência no Caps, definida pela equipe técnica, é de duas ou três 
vezes por semana. Em casos de maior necessidade, alguns usuários participam diariamente, situação considerada temporária pela referida equipe. Os usuários vêm ao Caps sempre nos mesmos dias da semana.

O número de participantes do grupo varia entre 10 a 15 pessoas, já que é aberta a entrada dos usuários presentes no Caps naquele dia, seguindo as características de grupos abertos ${ }^{7}$. A freqüência do grupo é semanal, e as sessões duram, em média, 45 minutos. As terapeutas do grupo são estagiárias do último ano de um curso de graduação em psicologia. $\mathrm{O}$ atendimento no Caps é uma das atividades de seu estágio curricular supervisionado, que tem duração de um ano letivo. Dessa maneira, as terapeutas do grupo mudam anualmente. Porém, os usuários já sabem da troca das estagiárias e as chamam de "joinhas", apontando o lugar das estagiárias de psicologia na instituição.

No lugar de observadora, a primeira autora deste artigo participou do grupo por um período de dois meses, no decorrer de oito sessões semanais ininterruptas do grupo psicoterapêutico.

\section{Os participantes}

Os participantes da pesquisa realizada são usuários do grupo psicoterapêutico descrito. Todos apresentam algum tipo de "transtorno mental"17, com diagnósticos nosográficos variados, e são egressos de internação psiquiátri$\mathrm{ca}$, em sua maioria. Todos recebem tratamento farmacológico gratuito no próprio Caps. Sua faixa etária varia entre 18 a 45 anos de idade, sendo todos adultos, de sexo masculino ou feminino, e pertencentes a estratos sociais de baixa renda.

\section{A construção de um corpus}

A construção do corpus foi realizada através da técnica de observação participante. O corpus foi constituído de oito relatos provenientes da transcrição das gravações em áudio das oito sessões em que a observadora participou do grupo. Obteve-se o Consentimento Livre e Esclarecido dos participantes do grupo, e o projeto da pesquisa foi aprovado e acompanhado pelo Comitê de Ética em Pesquisa da PUCRS.

Os resultados da pesquisa foram comunicados aos participantes, visando lhes dar um retorno do trabalho realizado e, ao mesmo tempo, obter sua confirmação no que se refere às considerações e às interpretações efetuadas.

\section{Análise}

A análise do corpus foi realizada com base no método de análise textual qualitativa proposto por Roque Moraes ${ }^{18}$. Esse método de análise possibilita o surgimento de uma compreensão renovada do corpus em um processo que envolve três fases. A primeira é a unitarização do corpus em unidades de sentido. A segunda é a reunião dessas unidades em categorias, chamada de categorização. A terceira é a construção de um metatexto em que as categorias são relacionadas entre si em um processo recursivo, possibilitando a emergência do argumento central da análise. A última versão desse metatexto tem a função de comunicar os resultados da análise 18, 19, 20, 21, 22 .

\section{Resultados e discussão}

Após a unitarização do corpus, foi realizada uma categorização inicial das unidades de sentido, e dela emergiram 25 categorias. Posteriormente, essas categorias foram ordenadas entre si e passaram a ser configuradas como categorias específicas e amplas. Tal categorização fundamentou-se no estabelecimento de relações entre as categorias, de acordo com os objetivos propostos na pesquisa, e sua ordenação foi realizada a um só tempo, em um processo "intuitivo"18, não seqüencial, nem linear.

As categorias amplas referem-se aos vínculos a que pertencem os usuários do grupo psicoterapêutico. Já as categorias específicas referem-se às suas maneiras de pertencer aos vínculos e a especificidades das pertenças, indicadas pelas categorias amplas.

Categorias amplas:

- Grupo: aglutina as categorias específicas participantes do grupo, compartilhamento no grupo e multidimensional.

- Caps: abrange a categoria específica multidimensional.

- Hospital psiquiátrico: engloba as categorias específicas louco e multidimensional.

- Família: engloba a categoria específica multidimensional.

- Sociedade: reúne as categorias específicas trabalhar e multidimensional.

Categorias específicas:

- Participantes do grupo: reúne categorias iniciais que aludem a participantes do grupo - terapeutas, observadora e gravador.

- Compartilhamento no grupo: refere-se ao que é compartilhado no espaço do grupo e aglu- 
tina as categorias iniciais grupo como família, descontrole no grupo, dor, recomendações e conselhos, falar e ouvir, falta, regras do Caps, entra e sai, quem é você.

- Louco: categoria inicial transformada em específica.

- Trabalho: categoria inicial transformada em específica.

- Multidimensional: reúne as categorias iniciais semelhanças e diferenças, tempo, roubo, ajuda, exibição pertinente, diagnóstico e doença, remédios.

Tais categorias relacionam-se a todas as categorias amplas, adquirindo, em cada uma delas, um sentido particular.

Os argumentos aglutinadores das categorias foram relacionados entre si, exemplificados com as falas dos participantes - cujos nomes foram alterados, exceto o da observadora - e com os aportes teóricos utilizados. As relações apresentadas no metatexto a seguir foram se construindo em um movimento recursivo de elaboração de sentidos; por isso, algumas categorias específicas estão explicitadas mais amplamente do que outras. Um exemplo disso é a categoria específica multidimensional, que está mais detalhada na categoria ampla grupo, já que foi a partir de sua da condição de usuários do grupo que os participantes da pesquisa foram investigados: grupo (categoria ampla); compartilhamento no grupo, multidimensional e participantes do grupo (categorias específicas).

Em cada sessão, os participantes do grupo "apresentavam-se" uns aos outros, no sentido apontado por Berenstein 11, de se mostrarem uns aos outros em sua radical novidade, o que torna cada encontro do grupo potencialmente estimulador da produção constante de subjetividade dos sujeitos que dele participam. Essa apresentação corresponde à categoria quem é você, que se refere aos questionamentos entre os participantes do grupo a respeito de quem são, o que sentem e fazem. Esse questionamento ocorre tanto em relação aos novos participantes, que surgem no entra e sai do grupo, à observadora e aos usuários novos, quanto em relação aos participantes já conhecidos que "se apresentam" 11 continuamente pelo compartilhamento de suas dores, que são as suas perdas, faltas, tristezas, dificuldades para dormir, agressividade, ver bichos, ouvir vozes, sentir culpa. $\mathrm{Na}$ tentativa de representar de alguma forma o sentimento de estranheza provocado pelo encontro com o alheio dos outros sujeitos ${ }^{14}$, os usuários passam a apontar suas semelhanças e diferenças, discutindo a trajetória da doença de cada um, seus diagnósticos, entendendo que, no grupo, têm dois, três tipos de doença, uns que têm depressão. São uns casos mais leves. É crônico, mas é mais leve, tem controle (6.IV.33 Joana). Buscam, também, nomear seus sentimentos e história pessoal desde a sua inserção como doentes, compreendendo os remédios que cada um toma e os sentimentos acerca do seu uso crônico. Entende-se, nesse sentido, o apontamento das semelhanças e diferenças como uma tentativa de representação, porque, através delas, o sujeito nomeia o outro a partir de si próprio, de acordo com aquilo que nos outros se assemelha ou difere dele mesmo ${ }^{15}$.

Outra reação frente à estranheza provocada pelo encontro com o alheio do outro consiste em não considerá-lo em sua singularidade. Berenstein 23 entende essa reação como uma forma de violência que ocorre no vínculo intersubjetivo.A categoria denominada roubo foi assim designada como uma metáfora de tal reação, já que se interpretou que, ao falarem em roubo, no grupo, os usuários também estivessem se referindo às tentativas dos outros sujeitos vinculados de dizerlhes como resolver seus problemas sem considerar seus sentimentos e opiniões. Porém, o sujeito não pode nunca ser negado em sua alteridade radical14. No grupo, Salete fala: Vocês não entendem, [...] vocês não imaginam a mínima história, gente, do que eu estou passando (Salete usuária do grupo - 1.I.108). Cada um tem um jeito (Luís - usuário do grupo - 8.II.40), como diz Luís, constatando a diversidade no grupo.

O grupo é entendido pelos usuários como um lugar de ajuda, onde debatem a necessidade de ajudar a si próprios e pedir ajuda quando precisam. Questionam-se sobre a quem pedi-la e citam alternativas de ajuda. Nas recomendações feitas uns aos outros, os participantes do grupo valorizam atitudes positivas de uns em relação aos outros e a sua maneira de se posicionarem no mundo. A maneira de comunicar os conselhos e recomendações também foi positiva, como, por exemplo: Tu não podes pensar assim, tu tens que pensar "hoje eu estou boa, estou legal" e colocar objetivo na tua vida, colocar objetivo de manhã cedo, "vou fazer isso e isso" $e$ fazer! (1.I.46b. Flávia aconselhando Salete - ambas usuárias do grupo).

Os usuários consideraram o grupo a mesma coisa que uma família. Nosso grupo é uma família. O que se fala aqui tem que ficar aqui dentro (Gelson - 6.IV.22). Essa idéia foi confirmada na devolução da análise da pesquisa ao grupo. A partir dela, só quem participa do grupo conhece 
os seus segredos, e conhecê-los designa a pertença ao grupo. Esta pode ser considerada uma "investidura referencial" 15 da pertença ao grupo, que forma o enquadre do grupo ${ }^{16}$, estabelecendo os limites internos e externos a ele. Porém, a comparação do grupo com a família restringe-se à idéia da manutenção do segredo como condição de pertença, não podendo ser generalizada.

Além da demarcação dos seus limites, os usuários questionam o grupo como espaço de compartilhamento. Cecília (7.VI.48), por exemplo, perguntou para as terapeutas (consideradas, nesse momento, as detentoras das normas do grupo) se os usuários poderiam trazer comida e comer durante a sessão. Tal fato ocorreu ao final da sétima sessão observada, em que os temas "comida" e "descontrole sobre o comer" mostraram-se centrais. Foi entendido como um questionamento dos usuários para as terapeutas - que detêm o poder formal de definir regras 24 - sobre a possibilidade de se descontrolarem no grupo.

Os participantes do grupo apontavam as faltas uns dos outros nas sessões, demonstrando a necessidade da presença, de uma ocupação possessiva 15 no vínculo e o "reconhecimento"14 de sua pertença ao grupo. Por exemplo, um usuário adverte: Se a pessoa não vem, não vem, eles pensam que a pessoa está boa, e daí dão alta. (Luís-3.V.38).

A relação grupo e Caps ficou evidenciada pelo predomínio das regras institucionais do Caps sobre as regras do grupo. Por exemplo, se eventos institucionais, como festas ou reuniões - em que os usuários do grupo participam -, são planejados no dia da sessão do grupo psicoterapêutico, esta é cancelada sem o questionamento prévio dos seus participantes. Kaës 25 considera que o grupo, ao mesmo tempo em que é continente do sujeito, é conteúdo de um meta-continente, que é a instituição. Esta é tomada como um conjunto de formas e estruturas sociais instituídas pela lei e pelo costume, que precede o grupo, regulando-o e determinando-o. No grupo investigado, o entra e sai de participantes e a valorização do uso de remédios pelos usuários são regras do Caps que se impõem sobre o grupo. Guanaes \& Japur ${ }^{26}$ alertam para que os serviços ambulatoriais se organizem e reflitam as práticas psicoterápicas realizadas em seus contextos, a fim de evitar o distanciamento de suas finalidades terapêuticas em função dos objetivos e da realidade institucional.

Quanto à ocupação de lugares na estrutura grupal que, de acordo com Seminotti27, define os sujeitos em relação uns aos outros, parece que no grupo os lugares são mais valorizados do que as pessoas que os ocupam, e o acolhimento do grupo é garantido pela sua estrutura mais do que pelas pessoas que a compõem. Essa característica decorre do entra e sai de usuários e profissionais tanto no grupo quanto no Caps, como afirma Joana: Se não tem um para atender, tem o outro. Não pode ficar só naquela expectativa de que uma pessoa vai atender (Joana - usuária - 1.I.33).

Porém, em relação às terapeutas, mesmo que o lugar de "joinhas" já estivesse definido no grupo, desde antes da sua chegada, os usuários questionavam a ocupação desse lugar por elas, destacando sua singularidade. Estas, por sua vez, em alguns momentos, falavam do grupo incluindo-se nele e, em outros, não, entendendo o grupo como entidade própria, independentemente de sua presença, como indica uma delas em sua fala: [...] o grupo está muito cuidadoso contigo, tentando te ajudar de todas as formas. E, aos pouquinhos, assim, a gente vai tentando te ajudar também (terapeuta Ana para usuária Salete 1.I.134).

Em relação a esta observadora, não havia esse lugar predefinido na estrutura vincular grupal: ele foi se constituindo aos poucos, na relação, pois era novo tanto para o grupo quanto para ela, que nunca havia participado do grupo. A presença da observadora no grupo constituiu-se em um excesso, algo que nunca houve anteriormente e que "interferiu" no grupo no sentido apontado por Berenstein 11 . De acordo com o autor, fatos novos, inscrições novas produzidas pela apresentação do outro sujeito, impõem-se a este, que precisa realizar um trabalho psíquico na tentativa de elaborá-los. Esse efeito ocorreu em todos os sujeitos vinculados, dado o caráter relacional da experiência.

O caráter relacional na estruturação de novos vínculos no grupo foi expresso nesse diálogo: Gelson (usuário) questiona: E a Cassandra, não fala nada para nós hoje? Ao que Nair complementa: Ela nunca conversa com ninguém. É seu jeito? E a observadora responde: Eu fico observando aqui e não falo nada, não é? A terapeuta Ana pergunta: Vocês esperavam que ela fosse falar, pessoal? Nair: Eu esperava que ela fosse falar alguma coisa, mas ela não fala nada. Observadora Cassandra: É importante eu poder colocar isso. Aquilo que a gente conversou de que o trabalho que eu estou fazendo é para conhecer o grupo. Por isso, estou mais quieta, para poder conhecer o grupo. Por isso, eu não falo. Gelson: Nós 
aqui estamos tudo bem, todos tomando o remédio certinho (Gelson, Cassandra, Nair, Ana 3.V.23).

Tendo sido questionada como sujeito, a pesquisadora respondeu como observadora, o que resultou em uma resposta de usuários e não de sujeitos, pois, se a função da pesquisadora é observar, a deles é tomar os remédios direitinho.

A resposta de Gelson também remete à percepção, pelos usuários do grupo, do lugar de observadora como o de uma avaliadora. A pergunta de Jair demonstra isso: E a Cassandra, está gostando do grupo ou não? (Jair - 6.IV.22). Kadis et al. 28 apontaram teoricamente essa reação frente à presença de um observador no grupo e consideraram que o seu silêncio poderia ser interpretado pelos usuários como uma forma de julgamento, do que poderiam se ressentir. Nesse sentido, constatamos que o processo de obtenção do Termo de Consentimento Livre e Esclarecido permitiu um enquadramento da participação da observadora no grupo, o que tranqüilizou a todos, como esclarece um trecho da última sessão observada. Cassandra: Que idéia vocês ficaram de eu ter vindo no grupo algumas vezes, ter gravado e agora deixar de participar? Gelson: Por mim, podia continuar junto com a gente. Luís: Aquele papel que eu li lá sobre a pesquisa, não é? Cassandra: Isso. Luís: Eu entendi que, com o tempo, você ia deixar a gente e depois, mais tarde, ia dar a resposta, eu entendi tudo (Cassandra, Luís e Gelson - 8.II.68).

Esse diálogo também aponta a questão da implicação afetiva da observadora durante sua participação no grupo, que, segundo Vieira Filho \& Teixeira ${ }^{29}$, propicia o elo entre o saber e a vivência afetiva do observador clínico durante o processo de construção do conhecimento.

Nas sessões de psicoterapia grupal, as terapeutas costumavam usar gravadores, o que justificou a escolha da gravação em áudio pela observadora. As sessões eram gravadas para serem posteriormente transcritas, tanto pela observadora, que as utilizaria na elaboração do corpus da pesquisa, quanto pelas terapeutas, que as transcreviam para a supervisão. Os usuários questionaram e apontaram o uso do gravador nas sessões, o que reportou aos vínculos das terapeutas com sua supervisora e aos da observadora com os destinatários da pesquisa que estava sendo realizada.

Caps (categoria ampla)

Multidimensional (categoria específica)

O uso de remédios pelos usuários é exigido como uma condição de pertença ao Caps. Ao mesmo tempo, a distribuição gratuita de medi- cação aos usuários pelo Caps estimula a sua freqüência regular na instituição.

O Caps foi considerado, pelos usuários, como um lugar de inserção social, comparado a uma família ou a um trabalho, tendo eles expressado a necessidade de valorizá-lo publicamente e também diante da observadora. Referiram que a sua participação nessa instituição estimulou uma nova ocupação na família, pois muitos familiares participam de atividades no Caps, como assembléias e grupos de familiares.

Os usuários demonstraram sentimentos ambivalentes: de vergonha pela sua participação no Caps, já que estão lá porque são doentes; e, ao mesmo tempo, de orgulho, já que ele é entendido como uma alternativa de tratamento em oposição ao hospital psiquiátrico. Isso indica uma investidura referencial dos usuários ao Caps, inserido no movimento da Reforma Psiquiátrica: Eu acho um absurdo isso. Eu não admito. Eles colocarem as pessoas lá no psiquiátrico. E a gente está aqui justamente para isso, para não internar mais naquele lugar (Flávia - usuária - 1.I.61).

Paradoxalmente, a maioria dos usuários do Caps só passou a integrá-lo após a internação psiquiátrica. Referiram que pretendem participar do Caps [...] até ficarmos velhinhos (Adílson - 8.II.74), o que remete a uma lógica parecida à da reclusão no hospital psiquiátrico, pois indica o Caps como única opção de tratamento. Ao mesmo tempo, eles pautam a discussão de suas semelhanças e diferenças em relação às pessoas que não são usuárias do Caps a partir de seus diagnósticos e doenças. Consideram que são doentes dos nervos, enquanto as outras pessoas têm outras doenças físicas.

Sociedade (categoria ampla)

Trabalhar e multidimensional (categorias específicas)

Os usuários indicaram a pertença ao Caps como uma maneira de se apresentarem na sociedade, a partir dos objetos artesanais lá produzidos, que são vendidos em feiras municipais, e da participação em eventos de saúde mental promovidos pelo Caps e por outras instituições municipais.

Com relação à sua pertença social, apresentaram como argumento aglutinador da categoria trabalhar a valorização da produção, entendida como trabalho ou estudo. Também referiram sentimentos de perda de relações sociais e impotência por não terem conseguido mais estudar ou trabalhar, e pela falta de dinheiro e aposentadoria, conforme o já apontado teoricamente por Ribeiro ${ }^{30}$. 
Nas relações sociais, apresentam sentimentos de ambivalência em relação ao uso dos remédios, que é condição de pertença nos outros vínculos e na sociedade, mas que é entendido como fator de discriminação e exclusão do mercado de trabalho. A exclusão do mercado de trabalho é uma das formas de violência, apontadas por Berenstein ${ }^{23}$, no mundo social, além das citadas pelos usuários, como o roubo, que aqui adquire o seu sentido concreto de violência social.

Hospital psiquiátrico (categoria ampla)

Louco e multidimensional (categorias específicas)

Em suas falas, os usuários consideraram o hospital psiquiátrico como o lugar dos loucos e relacionaram a loucura com descontrole: Quando dá aquele estado de loucura nele, é de loucura, é um estado de nervos que dá, incontrolável (Gilmar - usuário - 6. IV. 32). Essa idéia pode ter determinantes culturais, já que a perda de autonomia e de autogoverno é uma noção implicada no conceito de loucura, que variou pouco desde a antiguidade até os dias atuais ${ }^{31}$. Os usuários do grupo referiram o hospital psiquiátrico como lugar de ajuda na loucura, principalmente na falta de apoio familiar: Porque, se eu ficar doente da cabeça, a mãe já se foi, o pai já se foi. Eu acho, assim, que o meu lugar é só lá [hospital psiquiátrico]" (Vânia - 1.I.115).

Em uma das categorias de resultado de sua pesquisa sobre as representações dos usuários acerca do tratamento psiquiátrico, que foi intitulada "Tratar é ser cuidado/(des) cuidado", Mostazo \& Kirschbaum ${ }^{32}$ consideram os temas "tratamento psiquiátrico", "violência" e "instituição fechada”. Esses temas também se evidenciaram reiteradamente nas falas dos usuários do grupo, indicando a relação de presença que eles têm com o hospital psiquiátrico, mesmo estando - e querendo manter-se - fora dele. Os usuários demonstram entender o hospital psiquiátrico como lugar capaz de conter o seu descontrole na loucura, tanto que referem se apresentar de maneira mais agressiva nesse local, como afirma a usuária Vânia: Lá, no psiquiátrico, eu quebrei um vidro mesmo, mas, aqui no Caps ou na minha casa, eu nunca quebrei nada (Vânia - 6.IV.35). Essa ilustração refere-se à categoria exibição pertinente e remete à diversidade do sujeito e à sua adequação aos vínculos em que participa.

Ao mesmo tempo, eles se referem às marcas provenientes da experiência de [...] ficar muito tempo fechados lá (Gelson -1.I.60), aos maustratos sofridos e à dificuldade de retomarem a sua vida após a internação. Flávia comentou que: [...] a pessoa tem que ter estrutura para agüentar, senão sai pior do que entrou (Flávia - 1. I.80); assim como Vânia: [...] quando a gente está lá, eles enchem a gente com coisa na cabeça. Quando a gente sai, a gente sai com outros pensamentos. Chega em casa, a gente não consegue limpar a casa, não consegue nada. E aí a gente fica frágil, depois que sai do psiquiátrico (Vânia-1.I.59).

Família (categoria ampla)

Multidimensional (categoria específica)

Os usuários indicaram que sua ocupação de um lugar na família depende das relações que estabelecem com seus familiares. Dessa maneira, às vezes, posicionam-se como doentes, recebendo ajuda da família; em outras, posicionam-se como cuidadores, como Joana: $E u$ que pego o remédio dele [irmão], eu que vou ao centro de atendimento médico e pego e dou para ele (Joana - 4. III. 8). Em outros momentos, a família não permite essa ocupação, negligenciando suas opiniões e colocando-os na posição de doentes da casa, como relatou a usuária Vilma: Quando a gente vai falar uma coisa que a gente vê que está errado, a primeira coisa é que a gente começou a delirar. [...] Eles acham que, porque a gente não é são da cabeça, a gente já começa a delirar. Só eles são os certos, isso parte da minha família (Vilma - 7. VI. 5).

Berenstein \& Puget ${ }^{33}$ consideram que a família muitas vezes não reconhece a pertença do sujeito com transtorno mental grave porque ele evidencia um sentimento persecutório da $f a-$ mília, que, ao mesmo tempo em que tem no seu integrante a evidência de um prejuízo, teme ser por ele prejudicada. Dessa maneira, ao enfrentar ou opor-se ao pensamento de seus familiares, Vilma relata algo que, para eles, deveria permanecer oculto. A cisão da estrutura familiar entre os ditos sadios e os ditos doentes passa a defini-los enquanto sujeitos do vínculo 34 .

Bortoleto 35 investigou as representações de familiares de pacientes psicóticos sobre a doença mental, e concluiu que eles não consideram a sua participação no processo de adoecimento do paciente chamado psicótico, atribuindo suas causas a fatores externos à família, como influências místicas e religiosas.

Essa dificuldade não se restringe à família dos usuários, já que está de acordo com um modelo de saúde e doença vigente na sociedade atual, que diferencia totalmente o são e o enfermo, situando-os em pólos opostos. Assim, adoecer significa perder a saúde; o retorno do doente a seu estado anterior e ao exercício de 
suas funções na sociedade significa a cura, devendo o tratamento ser rápido, eficiente e circunscrito à área e à pessoa afetada 36 .

Diferentemente de seus familiares, os usuários entendem que a sua família também tem problemas, como explicita Cecília: A minha família está virada numa coisa, está pior que o Casseta e Planeta (6.IV.17 - Cecília - usuária). Também consideram que a ocupação de um lugar na família pode ajudá-los, como indica Flávia para Salete: Te anime, menina! Você tem tudo, você tem uma vida maravilhosa, você tem um maridão em casa. Chega em casa, faz uma comidinha para ele, faz uma comidinha para as tuas filhas. Não adianta, a vida é essa (1.I.48. Flávia - usuária).

A partir da relação entre as categorias amplas apresentadas, entende-se que os usuários do grupo psicoterapêutico investigado indicam as suas pertenças aos vínculos no próprio grupo psicoterapêutico, no Caps, em suas respectivas famílias, no hospital psiquiátrico e na sociedade. É necessário esclarecer que nesta pesquisa os sujeitos foram investigados a partir de sua pertença no grupo psicoterapêutico, uma de suas maneiras de ser. Se os investigássemos em outra posição, outras relações e modos de ocupação apareceriam, e, por que não dizer, os outros sujeitos, no sujeito, emergiriam.

O sentimento de pertença dos usuários ao grupo constitui-se pela pertença ao Caps, já que o grupo é uma de suas atividades. O Caps possibilita novas maneiras de pertencer na família e até na sociedade, porém estar doente ainda é a principal condição de pertença ao Caps e ao grupo, além da freqüência e uso da medicação. Mas os participantes da pesquisa diferenciam a condição de estar doente da condição de estar louco. Associam loucura com descontrole e, nessa situação, entendem o hospital psiquiátrico como o único lugar de ajuda.

O Caps é entendido pelos usuários como lugar de oposição ao hospital psiquiátrico. Entretanto, oposição também supõe uma relação, e o Caps e o hospital psiquiátrico situam-se nela como diametralmente opostos, porém linearmente interligadas. A lógica da doença, que é crônica, implica uma idéia de pertença fixa e permanente dos usuários ao Caps, o que impe-

\section{Colaboradores}

C Cardoso foi a responsável pela observação participante, concepção teórica, análise do corpus, e discussão dos resultados da pesquisa. $\mathrm{N}$ Seminotti foi o responsável pela orientação da pesquisa. de a sua procura por novas maneiras de pertencer que não estejam pautadas na doença.

Já no grupo, os usuários percebem a fragilidade de sua pertença, que não é fixa ou permanente; a pertença está mais relativizada, já que os usuários a entendem como mais uma, das muitas atividades realizadas no Caps. Essa compreensão permite a construção de novos tipos de vínculos e pertenças no grupo, uma vez que os usuários percebem que novas maneiras de pensar e de se relacionar não são inibidas no grupo, ao contrário, são estimuladas. No grupo, os usuários compartilham dores e experiências, apresentam-se em cada sessão e ensaiam novas maneiras de pertencer, entendendo que, assim como o grupo apresenta inúmeras composições, eles também são múltiplos e podem ocupar seus lugares nos múltiplos vínculos em que participam.

\section{Considerações finais}

A diversidade de pertenças das pessoas com transtornos mentais graves exige que os consideremos como sujeitos múltiplos, além da sua condição de doentes, o que remete a uma modificação nas teorias e práticas em saúde mental. A instauração dos Caps pelo Ministério da Saúde brasileiro, como recursos de atenção que visam à inserção das pessoas em seu território, coaduna-se com essa idéia.

Porém, o entendimento dos Caps como meros recursos terapêuticos de oposição ao modelo centrado no hospital psiquiátrico, operando em apenas uma lógica, que é a da doença, ainda persiste e precisa ser questionada. Nesse contexto, os grupos psicoterapêuticos, muito utilizados nos Caps, devem ser problematizados em sua complexidade e interdependência com a instituição e a realidade social em que se inserem, já que demonstraram ser um instrumento importante no estímulo à ampliação dos sujeitos que dele participam. Essa ampliação tem uma lógica diversa da lógica de inclusão, pois implica múltiplas inclusões de sujeitos, que, além de escolherem as suas maneiras de pertencer, também promovem a ampliação da pertença daqueles a quem se vinculam.

\section{Agradecimento}

À Capes, pela bolsa concedida à primeira autora. 


\section{Referências}

1. Leal EM. A experiência da violência na rede de assistência à saúde mental. In: Rauter $\mathrm{C}$, Passos E, Benevides R, organizadores. Clínica e política: subjetividade e violação dos direitos humanos. Rio de Janeiro: Instituto Franco Basaglia, TeCorá. p. 141-50.

2. Brasil. Ministério da Saúde. Secretaria de Atenção à Saúde. Departamento de Ações Programáticas Estratégicas. Saúde mental no SUS: os Centros de Atenção Psicossocial. Brasília: MS; 2004.

3. Lima MCP, Botega NJ. Hospital-dia: para quem e para quê? Rev Bras Psiquiatr 2001; 23 (4):195-99.

4. Brasil. Ministério da Saúde. Secretaria Executiva. Subsecretaria de Assuntos Administrativos. Coordenação Geral de Documentação e Informação. Legislação em Saúde Mental 1999-2001. 2a ed. Brasília: MS; 2001.

5. Lancetti A. Clínica grupal com psicóticos: a grupalidade que os especialistas não entendem. In: Lancetti A, organizador. Grupos e coletivos. São Paulo: Hucitec; 1993. p. 155-72. (SaúdeLoucura no 4).

6. Fernandes BS. Grupos em comunidade terapêutica e hospital psiquiátrico. In: Fernandes WJ, Svartman B, Fernandes BS, coordenadores. Grupos e configurações vinculares. Porto Alegre: Artmed; 2003. p. 261-8.

7. Vinogradov S, Yalom ID. Manual de psicoterapia de grupo. Porto Alegre: Artes Médicas; 1992.

8. Stone WN. Psicoterapia de grupo com enfermos mentais crônicos. In: Kaplan HI, Sadock BJ. Compêndio de psiquiatria de grupo. 3a ed. Porto Alegre: Artes Médicas; 1996. p. 348-56.

9. Bianchi G. Realidad vincular. In: Pachuk C, Friedler $\mathrm{R}$, coordenadores. Diccionario de psicoanálisis de las configuraciones vinculares. Buenos Aires: Ediciones Del Candil; 1998. p. 371-5.

10. Amenta M, Campi M, Goldchluk A, Postare F, Hamuy E, Villar V. Cambio psíquico en pacientes esquizofrênicos en tratamiento grupal. Vertex 2002; 13(50): 291-300.

11. Berenstein I. Devenir otro con otro(s): ajenidad, presencia, interferencia. Buenos Aires: Paidós; 2004.

12. Green A, organizador. Psicanálise contemporânea: revista francesa de psicanálise. Rio de Janeiro: Imago; 2003. p. 183-98.

13. Puget J. Intersubjetividad. Crisis de la representación. Revista de Psicoanálisis APdeBA [on line] 2003; XXV (1) [acessado em 19.10.2004]. Disponível em: http://www apdeba.org/publicaciones/2003.htm.

14. Berenstein I. Reflexões sobre uma psicanálise do vínculo. In: Green A, organizador. Psicanálise contemporânea: revista francesa de psicanálise. Rio de Janeiro: Imago; 2003. p. 183-98.

15. Puget J. Traumatismo social: memoria social y sentimiento de pertenencia. Memoria social-memoria singular. Rev Psicoanal 2000; 22(2):455-82.

16. Puget J, Bernard M, Chaves GG, Romano E. El grupo y sus configuraciones. Buenos Aires: Lugar Editorial; 1991.

17. Organização Mundial da Saúde. Classificação de transtornos mentais e de comportamento da CID10. Porto Alegre: Artes Médicas; 1993.
18. Moraes R. Uma tempestade de luz: a compreensão possibilitada pela análise textual discursiva. Ciência \& Educação 2003; 9(2):191-211.

19. Moraes R. Construindo quebra cabeças ou criando mosaicos? Aprendizagem e comunicação no processo de categorização. Porto Alegre: PUCRS; 2003. [Manuscrito inédito].

20. Moraes R. Passos para a criação de textos científicos. Porto Alegre: PUCRS; 2003. [Manuscrito inédito].

21. Moraes R. Movimentando-se entre as faces de Jano: comunicar e aprender na produção escrita que acompanha análises de pesquisas qualitativas. Porto Alegre: PUCRS; 2003. [Manuscrito inédito].

22. Moraes R. Mergulhos discursivos: análise textual qualitativa entendida como processo integrado de aprender, comunicar e interferir em discursos. Porto Alegre: PUCRS; 2003. [Manuscrito inédito].

23. Berenstein I. Notas sobre la violencia. Rev Psicoanal $2000 ; 22(2): 257-71$

24. Pasqualini G. Las éticas y los encuadres. Rev Psicoanal 26(1):139-47.

25. Kaës R. Realidade psíquica e sofrimento nas instituições. In: Käes R, Bleger J, Enriquez E, Fornari F, Fustier P, Rousillon R, et al. A instituição e as instituições. São Paulo: Casa do Psicólogo; 1991. p. 19-58.

26. Guanaes C, Japur M. Fatores terapêuticos em um grupo de apoio para pacientes psiquiátricos ambulatoriais. Rev Bras Psiquiatr 2001; 23(3):134-40.

27. Seminotti N. La organización y dinámica del grupo psicológico: la multiplicidad/diversidad de organizadores del grupo [tese]. Madrid: Universidad Autónoma de Madrid; 2000.

28. Kadis AL, Krasner JD, Winick C, Foulkes SH. Psicoterapia de grupo. 3a ed. São Paulo: Ibrasa; 1976.

29. Vieira Filho NG, Teixeira VMS. Observação Clínica: estudo da implicação psicoafetiva. Psicol Estud 2003; $8(1): 23-9$.

30. Ribeiro MA. Atelier de trabalho para psicóticos. Uma possibilidade de atuação em orientação profissional. Psicologia Ciência e Profissão 1998; 18(1):12-27.

31. Pessoti I. Os nomes da loucura. São Paulo: Ed. 34; 1999.

32. Mostazo RR, Kirschbaum DIR. Usuários de um Centro de Atenção Psicossocial: um estudo de suas representações sociais acerca de tratamento psiquiátrico. Rev Lat Am Enfermagem 2003; 11(6):786-91.

33. Berenstein I, Puget J. Lo vincular: clínica y técnica psicoanalítica. Buenos Aires: Paidós; 1997.

34. Berenstein I. Família e doença mental. São Paulo: Escuta; 1988.

35. Bortoleto V. Representações de familiares de pacientes psicóticos sobre a doença mental através do discurso do sujeito coletivo. Psicologia Hospitalar 2004; 2(1):9-21.

36. Fascioli L. $i$ Participar en un grupo? Y eso... i me puede curar? Tramas: Perspectiva Psicoanalítica Vincular 1998; (4):87-104.

Artigo apresentado em 16/05/2005

Aprovado em 30/06/2005

Versão final apresentada em 18/07/2005 